\title{
(C) OPEN ACCESS \\ Can patients contribute to safer care in meetings with healthcare professionals? A cross-sectional survey of patient perceptions and beliefs
}

\author{
Carin Ericsson, ${ }^{\circledR 1,2}$ Janna Skagerström, ${ }^{2,3}$ Kristina Schildmeijer, $^{4}$ \\ Kristofer Årestedt, ${ }^{4,5}$ Anders Broström, ${ }^{6,7}$ Amir Pakpour, ${ }^{6,8}$ Per Nilsen ${ }^{2}$
}

- Additional material is published online only. To view please visit the journal online (http://dx.doi.org/10.1136/ bmjqs-2018-008524).

For numbered affiliations see end of article.

\section{Correspondence to} Carin Ericsson, Cardiology and Speciality Medicine Centre, Region Ostergotland, Linkoping 581 91, Sweden;

Carin.Ericsson@

regionostergotland.se

Received 28 June 2018 Revised 5 March 2019 Accepted 6 April 2019 Published Online First 24 April 2019
Check for updates

(C) Author(s) (or their employer(s)) 2019. Re-use permitted under CC BY-NC. No commercial re-use. See rights and permissions. Published by BMJ.

To cite: Ericsson $C$, Skagerström J, Schildmeijer K, et al. BMJ Qual Saf 2019;28:657-666

\begin{abstract}
Objectives To investigate patients' perceptions of their meetings with healthcare professionals and the extent to which they believe they can influence patient safety in these meetings.

Design Cross-sectional survey of patients using a study-specific questionnaire. Data were analysed using both parametric and non-parametric statistics.

Setting The study was conducted in primary and secondary care in three county councils in southeast Sweden by means of a survey questionnaire despatched in January 2017.

Participants Survey data were collected from 1445 patients, 333 of whom were complainants (patients who had filed a complaint about being harmed in healthcare) and 1112 regular patients (patients recruited from healthcare units).

Main outcome measures Patients' perceptions of meetings with physicians and nurses, beliefs concerning patients' contributions to safer care and whether the patients had suffered harm in healthcare during the past 10 years.

Results Most respondents reported that it was easy to ask physicians and nurses questions $(84.9 \%$ and $86.6 \%$ ) and to point out if something felt odd in their care $(77.7 \%$ and $80.7 \%)$. In general, complainants agreed to a higher extent compared with regular patients that patients can contribute to safer care (mean 1.92 and 2.13, p<0.001). Almost one-third $(31.2 \%)$ of the respondents (both complainants and regular patients) reported that they had suffered harm in healthcare during the past 10 years.

Conclusions Most respondents believed that healthcare professionals can facilitate patient interaction and increase patient safety by encouraging patients to ask questions and take an active part in their care. Further research will need to identify strategies to support such questioning in routine practice and ensure that it achieves its intended goals.
\end{abstract}

\section{BACKGROUND}

Patient involvement to achieve safer care is an area of increasing policy, research, healthcare management and practice interest in numerous countries. The assumption is that patients' involvement in their own treatment or care can improve patient safety. ${ }^{1-3}$ This is based on the premise that patients are privileged witnesses of their care in the sense that they are at the centre of the treatment process and, unlike healthcare professionals, observe the whole process of care. ${ }^{4}$ Involving patients in their own care has been an integral part of numerous international patient safety campaigns, including WHO's Patients for Patient Safety ${ }^{5}$ and programmes undertaken by the Joint Commission in US hospitals, for example, the Speak Up initiatives. ${ }^{6}$ In Sweden, the National Board of Health and Welfare and Swedish Association of Local Authorities and Region, representing the county councils and municipalities, have emphasised the importance of patient involvement. ${ }^{78}$

Research has shown that the relationship and communication between patients and healthcare professionals is important for patients' willingness to engage in safety-related behaviours. A poor relationship with healthcare professionals makes patients less motivated to engage with their safety. ${ }^{9}{ }^{10}$ Patients' perceptions of their role and status as subordinate to the healthcare professionals have been identified as a barrier to patients' involvement in error reduction efforts. ${ }^{11}$ Furthermore, if patients perceive their role to be that of passive recipient of medical expertise, they are unwilling to engage actively with their safety by challenging healthcare professionals about their practice. $^{12} 13$ Other factors that influence 
patients' involvement in their own safety include the patients' illness, their perception of the risk of error in their treatment ${ }^{14}$ and various organisational factors. ${ }^{11}$

Research on various forms of patient involvement has been conducted using a number of similar and partially overlapping concepts, including 'patient participation', 'patient partnership' and 'patient engagement'. Hence, it is crucial to clearly specify what types of involvement are investigated. ${ }^{15}$ The research described in this paper focuses on the interaction between patients and healthcare professionals in their regular meetings in various healthcare settings, for example, conversations between nurses and bedded patients in hospital wards or between physicians and patients in primary healthcare consultations. Previous research on patient involvement for safer care has addressed several aspects of interactive and non-interactive behaviours such as speaking up, choice of provider, self-medication, decision-making and self-monitoring. ${ }^{1} 21617$ However, there is limited knowledge concerning how patients themselves believe they can contribute to safer care by interacting with healthcare professionals in regular meetings in healthcare. More research is needed to understand under what conditions patients believe they can contribute to safer care by interacting in meetings with healthcare professionals. ${ }^{18}$ This study addresses important knowledge gaps in research on patient involvement of potential relevance for patient safety. The aim was to investigate patients' perceptions of the interaction in meetings with healthcare professionals in different healthcare settings in Sweden and the extent to which they believe they can influence patient safety in these meetings.

\section{METHODS}

\section{Study design and setting}

The study was a cross-sectional survey using a patient self-reported questionnaire. The setting for the study was Swedish healthcare, which is mainly publicly funded although private healthcare also exists. All residents are insured by the state, with equal access for the entire population. The responsibility for health and medical care in Sweden is shared by the central government, county councils and municipalities throughout Sweden. The healthcare system is financed primarily through taxes levied by county councils and municipalities.

\section{Participants}

Two categories of patients took part in the study: patients who had filed a complaint to the Health and Social Care Inspectorate (HSCI) that they had been physically or mentally harmed in healthcare (referred to as 'complainants') and patients who received healthcare in six healthcare facilities during 2016 (referred to as 'regular patients'). The two patient groups were recruited from the same three county councils in southeast Sweden.
Complainants were recruited from HSCI, which is a governmental agency responsible for supervising healthcare, social services and activities under the Act concerning Support and Service for Persons with Certain Functional Impairments. ${ }^{19}$ The goal of the HSCI is to improve patient safety in all areas of Swedish healthcare. Patients and next of kin can file a complaint to the HSCI if they have experienced harm that they attribute to the health services or if they have experienced deficient patient safety in connexion with care or treatment in the healthcare or dental care system. The complaint must be filed within 2 years of the occurrence. The HSCI investigates the event(s) and does not focus solely on the actions of the healthcare system and/or the healthcare professionals. The objective is to assess whether something went wrong and, if so, why. A complaint report could, for example, concern the lack of, delayed and/or incorrect diagnosis and treatment, deficient referrals, deficient medical treatment, incorrectly executed treatment, infections resulting from care and fall-related injuries that occur in connexion with care or treatment.

The HSCI provided lists of patients. Inclusion criteria were age 18 years or more and having submitted a complaint in any of the three county councils between 2013 and 2015. After eliminating duplicates, patients with temporary social security numbers, the deceased and those who had relocated were eliminated, 614 complainants remained.

To achieve a heterogeneous sample of patients, regular patients were recruited from six healthcare facilities: a pulmonary medical department at a university hospital (550 beds); a surgery department in a mid-sized hospital (350 beds); a rheumatology department in a university hospital (550); a maternity care unit; two primary healthcare units. This purposeful sampling strategy was used to ensure that the study included patients who represented a broad spectrum of perceptions and experiences concerning patient involvement in relation to patient safety. Study participants had made an individual visit or been an inpatient at any of the six units.

With regard to the regular patients, appointment lists of patients who had visited the units during 2016 were obtained from the six participating healthcare units. Inclusion criteria were age 18 years or more, having had a scheduled appointment or having been an inpatient at any of the units in 2016 and having a Swedish social security number. Each unit was asked to provide a list of 400 consecutive patients organised according to the date of the visit. After elimination of duplicates, patients with only temporary social security numbers, the deceased and those who had relocated, 1898 regular patients remained.

\section{Data collection and questionnaire}

In January 2017, a study-specific questionnaire was sent by regular mail to 2512 patients (614 complainants 


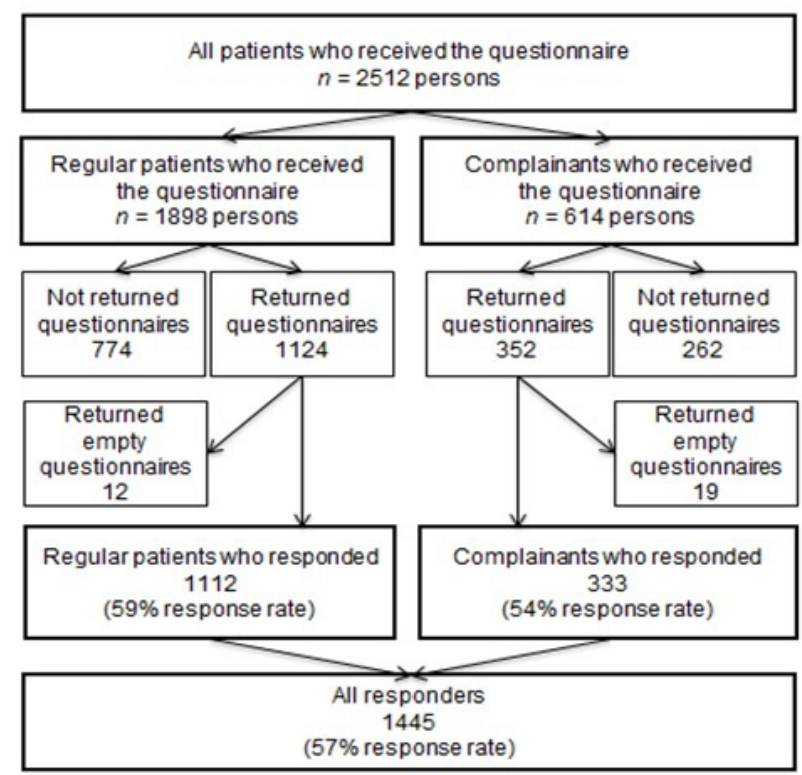

Figure 1 Study population and responders.

and 1898 regular patients). Along with the questionnaire, the patients received a letter containing information on the study: that it was voluntary to participate, that returning the questionnaire counted as giving consent to participate and that the data were handled confidentially. Two reminders were sent, the first 2 weeks after the initial mailing and the second 2 weeks later. A total of 1476 patients returned the questionnaire. After 31 empty questionnaires were discarded, the total number of respondents was 1445 (response rate 57\%). Of these, 333 were complainants (response rate 54\%) and 1112 were regular patients (response rate 59\%) (figure 1). The completed questionnaires were scanned by the university's printing and scanning facility.

The study-specific questionnaire was developed by the researchers behind the study following a literature review that showed that there were no existing instruments addressing the issues under study. Details of the development and contents of the questionnaire are provided in a methodological online supplementary appendix. ${ }^{17}$ 20-25 The final questionnaire consisted of 14 questions, of which 13 were closed-ended and 1 was open-ended. Eleven questions were analysed for this study.

To ascertain satisfactory content validity of the questionnaire and that no important aspects were neglected, the questionnaire was inspected by three experienced experts in patient safety (all three having conducted patient safety research and worked with these issues at local and national levels) and one survey questionnaire expert (with a PhD degree focused on survey methodology). Revisions were made to ensure that the questions were well formulated and easy to comprehend. Seven patients recruited from one primary care unit and one hospital unit then answered the questionnaire using Think-aloud interviews. ${ }^{26}$ They were also interviewed afterwards about how they interpreted the questions. The patients were of different ages and had different experiences of healthcare. The interviews showed that a few minor modifications were required concerning two questions. The first question concerned frequency of visit/hospitalisation in the healthcare in the last 12 months. However, this was found to be difficult to answer and was revised accordingly to focus on types of care unit the patient had been in contact with the last 12 months. The other question concerned how the patient perceived the response from the healthcare professionals at the last visit. This was simplified and shortened from six to three items due to the risk for misunderstanding.

\section{Data analysis}

No imputation has been made for missing data. Data were analysed using both parametric and non-parametric statistics depending on the level and distribution of data. Background and study variables were presented with descriptive statistics. Despite the ordinal nature of data, the questions about patients' perceptions of contribution to safer care are presented with mean and SD rather than median and quartiles to facilitate the interpretation. Comparisons between regular patients and complainants, as well as comparisons between patients' meetings with physicians and meetings with nurses, were analysed using an independent sample t-test, Mann-Whitney $U$ test or Pearson $\chi^{2}$ test. Fisher's exact test (adjusted for $2 \times 3$ tables) was applied when the assumption for Pearson $\chi^{2}$ test was violated. The two questions concerning the respondent's perceptions of encounters with physicians and nurses in healthcare were dichotomised into 'easy' ('very easy' and 'quite easy') and 'difficult' ('quite difficult' and 'very difficult') before analysis. A p value $<0.05$ was considered statistically significant. All analyses were performed with Stata V.15.1 (StataCorp, College Station, Texas, USA).

\section{RESULTS}

\section{Sample characteristics}

The total number of respondents was 1445 , of whom 333 were complaints and 1112 were regular patients. The mean age was 59.8 years (SD 17.9 years; range, 18-98 years) and almost two-thirds of all respondents were women $(\mathrm{n}=931,65.2 \%)$. The regular patients were significantly older than the complainants (mean difference, 3.3 years; $\mathrm{p}=0.004$ ). Most of the respondents had upper secondary education or higher $(\mathrm{n}=998,71.1 \%)$, but regular patients had significantly lower educational level than complainants $(\mathrm{p}=0.005)$. Half of the respondents were retired $(n=725,50.2 \%)$ and one-third were working $(n=478,33.1)$ The most common setting for visits to healthcare in the last 12 months was primary care, followed by a hospital unit and hospital inpatient care. The median value for 
Table 1 Characteristics of the participants

\begin{tabular}{|c|c|c|c|c|c|}
\hline & Valid data, $\mathrm{n}$ & $\begin{array}{l}\text { All patients } \\
(\mathrm{n}=1445)\end{array}$ & Complainants $(n=333)$ & Regular patients $(n=1112)$ & $P$ value \\
\hline Age, mean (SD) (range) & 1435 & $59.8(17.9)(18-98)$ & $57.3(16.4)(22-96)$ & $60.6(18.3)(18-98)$ & $0.004^{*}$ \\
\hline Sex, $\mathrm{n}(\%)$ & 1428 & & & & $0.374 \dagger$ \\
\hline Female & & $931(65.2)$ & $220(66.7)$ & $711(64.8)$ & \\
\hline Male & & $495(34.7)$ & $109(33.0)$ & $386(35.2)$ & \\
\hline Other gender identity & & $2(0.1)$ & $1(0.3)$ & $1(0.1)$ & \\
\hline Education level, n (\%) & 1404 & & & & $0.005 \ddagger$ \\
\hline Primary school & & $406(28.9)$ & $70(21.7)$ & $336(31.1)$ & \\
\hline Upper secondary school & & $555(39.5)$ & $138(42.9)$ & $417(38.5)$ & \\
\hline University & & $443(31.6)$ & $114(35.4)$ & $329(30.4)$ & \\
\hline Occupation, n (\%)§ & 1445 & & & & \\
\hline Working & & $478(33.1)$ & $114(34.2)$ & $364(32.7)$ & $0.610 \ddagger$ \\
\hline Retired & & $725(50.2)$ & $151(45.4)$ & $574(51.6)$ & $0.045 \ddagger$ \\
\hline Studying & & $32(2.2)$ & $10(3.0)$ & $22(2.0)$ & $0.265 \ddagger$ \\
\hline Job-seeker & & $26(1.8)$ & $8(2.4)$ & $18(1.6)$ & $0.345 \ddagger$ \\
\hline Sick leave & & $112(7.8)$ & $50(15.0)$ & $62(5.6)$ & $<0.001 \mp$ \\
\hline \multicolumn{6}{|c|}{$\begin{array}{l}\text { Healthcare visits in the last } 12 \text { months, } 1445 \\
n(\%) \S\end{array}$} \\
\hline Primary care or maternity care & & $1139(78.8)$ & $240(72.1)$ & $899(80.9)$ & $0.001 \neq$ \\
\hline Occupational healthcare & & $71(4.9)$ & $20(6.0)$ & $51(4.6)$ & $0.293 \ddagger$ \\
\hline Hospital unit & & $1006(69.6)$ & $218(65.5)$ & $788(70.9)$ & $0.060 \ddagger$ \\
\hline Hospital inpatient care & & $555(38.4)$ & $96(28.8)$ & $459(41.3)$ & $<0.001 \ddagger$ \\
\hline $\begin{array}{l}\text { Self-rated health, median (q1-q3) } \\
\text { (mean rank) }\end{array}$ & 1412 & $3(3-4)$ & $4(3-4)(797.2)$ & $3(3-4)(679.5)$ & $<0.001^{* *}$ \\
\hline \multicolumn{6}{|c|}{$\begin{array}{l}\text { *Independent sample t-test. } \\
\text { †Fisher's exact test, adjusted for } 2 \times 3 \text { tables. } \\
\text { ¥Pearson's } \chi^{2} \text { test. } \\
\text { §More than one option is possible. } \\
\text { १Measured with SF-1, possible range } 1-5 \text { (1, excellent health; } 5 \text {, poor health). } \\
\text { **Mann-Whitney U test. }\end{array}$} \\
\hline
\end{tabular}

self-rated health was 3 ('good') among all patients. However, regular patients scored significantly better health than complainants $(\mathrm{p}<0.001)$ (table 1$)$.

\section{Experiences of encounters with healthcare professionals}

Experiences of encounters with physicians and nurses are presented in table 2. Most of the respondents (complainants and regular patients) replied that it was easy to ask the physician and the nurse for information $(84.9 \%$ vs $86.6 \%)$ and to say if something seemed odd with the treatment or care $(77.7 \%$ vs $80.7 \%)$. It was less easy to tell the physician or the nurse if she/he had made a mistake (39.9\% vs $47.2 \%)$.

In comparison with the physician, it was significantly easier for the respondents to ask the nurse for information $(\mathrm{p}<0.001)$, say to the nurse if something seemed odd $(p<0.001)$ and telling the nurse if she/he had make a mistake $(\mathrm{p}<0.001)$.

In comparison with the complaints, regular patients reported that it was easier to ask the physician and nurse for information $(\mathrm{p}<0.001$ and $\mathrm{p}=0.001$, respectively) and say to the physician and nurse if something seemed odd with the treatment or care $(p<0.001$ and $\mathrm{p}=0.003$, respectively). Regarding the question on telling the physician or nurse she/he had made any mistake, no differences were shown between complainants and regular patients $(\mathrm{p}=0.625$ and $\mathrm{p}=0.700$, respectively).

\section{Beliefs regarding patients' contribution to safer care}

The respondents (complainants and regular patients) had favourable beliefs of patients' abilities to contribute to safer care (table 3). The complainants had more positive beliefs than regular patients that they could contribute to making healthcare safer (mean difference $0.21, \mathrm{p}<0.001$ ), that patients who ask questions can contribute to safer healthcare (mean difference $0.16, \mathrm{p}<0.001$ ) and that patients have a responsibility to point out shortcomings in their care or treatment that the healthcare professionals do not recognise (mean difference $0.26, \mathrm{p}<0.001$ ). Despite this, the complainants believed to a greater extent than regular patients that patients who ask questions or notify healthcare professionals about shortcomings in their care or treatment risk receiving worse care than other patients (mean difference $0.49, \mathrm{p}<0.001$; mean difference $0.53, \mathrm{p}<0.001)$. No significant difference 
Table 2 Experiences of encounters with physicians and with nurses in healthcare: "How do you usually experience your meetings with physicians/nurses in healthcare?"

\begin{tabular}{|c|c|c|c|c|c|}
\hline & Valid data, n & $\begin{array}{l}\text { All patients }(\%) \\
(n=1445)\end{array}$ & $\begin{array}{l}\text { Complainants } \\
(\%) \\
(\mathrm{n}=333)\end{array}$ & $\begin{array}{l}\text { Regular patients } \\
(\%) \\
(n=1112)\end{array}$ & $P$ value* \\
\hline $\begin{array}{l}\text { Asking the physician questions to get information about my } \\
\text { illness or treatment is... }\end{array}$ & 1406 & & & & $<0.001$ \\
\hline Easy & & $1194(84.9)$ & $233(73.0)$ & 963 (89.9) & \\
\hline Difficult & & $194(13.8)$ & $86(27.0)$ & $108(10.1)$ & \\
\hline Don't know & & $18(1.3)$ & $\mathrm{n} / \mathrm{a}$ & $\mathrm{n} / \mathrm{a}$ & \\
\hline $\begin{array}{l}\text { Asking the nurse questions to get information about my } \\
\text { illness or treatment is... }\end{array}$ & 1413 & & & & 0.001 \\
\hline Easy & & $1223(86.6)$ & $257(85.7)$ & $966(91.8)$ & \\
\hline Difficult & & $129(9.1)$ & $43(14.3)$ & $86(8.2)$ & \\
\hline Don't know & & $61(4.3)$ & $\mathrm{n} / \mathrm{a}$ & $\mathrm{n} / \mathrm{a}$ & \\
\hline P value* & & $<0.001$ & & & \\
\hline $\begin{array}{l}\text { Telling the physician if I recognise something that seems } \\
\text { odd (or is difficult to understand) in my treatment or care } \\
\text { is... }\end{array}$ & 1356 & & & & $<0.001$ \\
\hline Easy & & $1053(77.7)$ & 214 (69.9) & $839(84.9)$ & \\
\hline Difficult & & $241(17.8)$ & $92(30.1)$ & $149(15.1)$ & \\
\hline Don't know & & $62(4.6)$ & $\mathrm{n} / \mathrm{a}$ & $\mathrm{n} / \mathrm{a}$ & \\
\hline $\begin{array}{l}\text { Telling the nurse if I recognise something that seems odd } \\
\text { (or is difficult to understand) in my treatment or care is... }\end{array}$ & 1375 & & & & 0.003 \\
\hline Easy & & $1110(80.7)$ & $242(82.3)$ & $868(88.9)$ & \\
\hline Difficult & & $160(11.6)$ & $52(17.7)$ & $108(11.1)$ & \\
\hline Don't know & & 105 (7.6) & $\mathrm{n} / \mathrm{a}$ & $\mathrm{n} / \mathrm{a}$ & \\
\hline P value* & & $<0.001$ & & & \\
\hline Telling the physician if she/he makes a mistake is... & 1349 & & & & 0.625 \\
\hline Easy & & $534(39.6)$ & $145(51.1)$ & $389(49.4)$ & \\
\hline Difficult & & $538(39.9)$ & $139(48.9)$ & $399(50.6)$ & \\
\hline Don't know & & $277(20.5)$ & $\mathrm{n} / \mathrm{a}$ & $\mathrm{n} / \mathrm{a}$ & \\
\hline Telling the nurse if she/he makes a mistake is.. & 1345 & & & & 0.700 \\
\hline Easy & & $635(47.2)$ & $170(60.9)$ & $465(59.6)$ & \\
\hline Difficult & & $424(31.5)$ & $109(39.1)$ & $315(40.4)$ & \\
\hline Don't know & & $286(21.3)$ & $\mathrm{n} / \mathrm{a}$ & $\mathrm{n} / \mathrm{a}$ & \\
\hline P value* & & $<0.001$ & & & \\
\hline
\end{tabular}

${ }^{*}$ Pearson's $\chi^{2}$ test.

n/a, not applicable (not included in the significant test and therefore not reported).

was detected regarding the belief that it is easier for patients to ask questions if they are encouraged to do so by the healthcare professionals (mean difference $0.05, \mathrm{p}=0.295)$.

\section{Perceived harm and avoidability of harm}

Almost one-third ( $\mathrm{n}=408,31.2 \%)$ of the respondents (complainants and regular patients) reported that they had suffered harm in healthcare in the last 10 years. The proportion was significantly higher among the complainants than the regular patients $(\mathrm{n}=251,78.2 \%$ vs $n=157,15.9 \% ; p<0.001)$. Of those who reported that they had been harmed, two of three complainants $(n=165,68.8 \%)$ and almost half of the regular patients $(n=70,46.1 \%)$ stated that the harm in the latest harm episode could have been avoided if healthcare professionals had listened to them $(\mathrm{p}<0.001)$ (table 4$)$.

\section{DISCUSSION}

The aim of the study was to investigate patients' perceptions of their meetings with healthcare professionals and the extent to which they believe they can influence patient safety in these meetings. There has been a progression towards increased patient involvement and participation in decision-making in healthcare. ${ }^{27}$ Research from the patient perspective has shown that patients are more willing to interact if healthcare professionals actively seek their views ${ }^{28}$ and that patients are motivated and willing to engage in an intervention designed to support them to collaborate with healthcare professionals in order to reduce the risk of harm and improve patient safety. ${ }^{29}$ We found that, to a large extent, the participants believed that patients can contribute to making healthcare safer by interacting with the healthcare professional in 
Table 3 Patients' contribution to safer care

\begin{tabular}{|c|c|c|c|c|c|}
\hline & & Score distrib & mean (SD) & & \\
\hline & Valid data, n & $\begin{array}{l}\text { All patients } \\
(n=1445)\end{array}$ & $\begin{array}{l}\text { Complainants } \\
(\mathrm{n}=333)\end{array}$ & $\begin{array}{l}\text { Regular patients } \\
(\mathrm{n}=1112)\end{array}$ & $P$ value* \\
\hline $\begin{array}{l}\text { I believe I as a patient can contribute to making } \\
\text { healthcare safer }\end{array}$ & 1368 & $2.08(0.89)$ & $1.92(0.93)$ & $2.13(0.88)$ & $<0.001$ \\
\hline $\begin{array}{l}\text { I believe patients who ask questions can } \\
\text { contribute to safer healthcare }\end{array}$ & 1368 & $1.84(0.82)$ & $1.71(0.85)$ & $1.87(0.80)$ & $<0.001$ \\
\hline $\begin{array}{l}\text { I believe patients who ask questions risk receiving } \\
\text { worse care than other patients }\end{array}$ & 1320 & $3.51(0.83)$ & $3.13(1.06)$ & $3.62(0.71)$ & $<0.001$ \\
\hline $\begin{array}{l}\text { I believe it is easier for patients to ask questions } \\
\text { if they are encouraged to do so by the healthcare } \\
\text { professionals }\end{array}$ & 1361 & $1.71(0.84)$ & $1.67(0.83)$ & $1.72(0.85)$ & 0.295 \\
\hline $\begin{array}{l}\text { I believe patients who notify healthcare } \\
\text { professionals about shortcomings in their care } \\
\text { or treatment risk getting worse care than other } \\
\text { patients }\end{array}$ & 1330 & $3.19(0.91)$ & $2.78(1.08)$ & $3.31(0.81)$ & $<0.001$ \\
\hline $\begin{array}{l}\text { I believe patients have a responsibility to point out } \\
\text { shortcomings in their care or treatment that the } \\
\text { healthcare professionals do not recognise }\end{array}$ & 1354 & $1.70(0.86)$ & $1.50(0.81)$ & $1.76(0.87)$ & $<0.001$ \\
\hline
\end{tabular}

meetings to receive treatment or care. They reported that it is easy to ask healthcare professionals questions regarding their illness or treatment and to point out if something feels odd in their treatment or care. More than half of the respondents who had sustained harm in healthcare within the last 10 years reported that the latest harm episode could have been avoided if the healthcare professionals had listened to them.

In general, the respondents agreed that it is easier to participate in their treatment or care if they are encouraged to do so by healthcare professionals. This finding is consistent with previous research. ${ }^{11} 27$ Davis $e t a l^{17}$ found that concerted efforts might be needed to encourage patients in the UK to participate in their care, particularly in situations where patients perceive that they are challenging the authority of healthcare professionals. Earlier studies conducted in Sweden ${ }^{21} 22$ have shown that physicians and nurses in Swedish healthcare believe that healthcare professionals have the responsibility to actively invite patients to ask questions. Our studies ${ }^{21} 2230$ have shown that the professionals are largely positive about patient involvement for safer care and believe that they have an important role in creating a climate that facilitates patient involvement. Similarly, Grünloh $e t a l^{31}$ have suggested that healthcare professionals can help patients improve their health literacy by inviting them to ask questions, thus providing an opportunity to

Table 4 Harm in the last 10 years and avoidability of harm in the latest harm episode

\begin{tabular}{|c|c|c|c|c|c|}
\hline & Valid data, n & $\begin{array}{l}\text { All patients }(\%) \\
(n=1445)\end{array}$ & $\begin{array}{l}\text { Complainants } \\
(\%) \\
(\mathrm{n}=333)\end{array}$ & $\begin{array}{l}\text { Regular patients } \\
(\%) \\
(n=1112)\end{array}$ & P value* \\
\hline Self-reported harm in the last 10 years & 1306 & & & & $<0.001$ \\
\hline Yes & & $408(31.2)$ & $251(78.2)$ & $157(15.9)$ & \\
\hline No & & $823(63.0)$ & $56(17.5)$ & $767(77.9)$ & \\
\hline Don't know & & $75(5.7)$ & $14(4.4)$ & $61(6.2)$ & \\
\hline $\begin{array}{l}\text { Perceived avoidability of harm in the latest harm } \\
\text { episodet }\end{array}$ & 392 & & & & $<0.001$ \\
\hline $\begin{array}{l}\text { Avoidable: the harm could have been avoided if the } \\
\text { healthcare professionals had listened to me }\end{array}$ & & $235(59.9)$ & $165(68.8)$ & $70(46.1)$ & \\
\hline $\begin{array}{l}\text { Possibly avoidable: the harm could possibly have } \\
\text { been avoided if the healthcare professionals had } \\
\text { listened to me }\end{array}$ & & $82(20.9)$ & $42(17.5)$ & $40(26.3)$ & \\
\hline $\begin{array}{l}\text { Unavoidable: the harm could not have been avoided } \\
\text { even if the healthcare professionals had listened } \\
\text { to me }\end{array}$ & & $75(19.1)$ & $33(13.8)$ & $42(27.6)$ & \\
\hline
\end{tabular}


ask critical questions and also questions that can help the patients understand their situation, thus making them more able to participate in their care. A study conducted in the USA by Rathert et al ${ }^{32}$ showed that open and timely communication about patients' health status was rarely achieved, which negatively impacted on the patients' sense of safety.

The respondents in our study found it more difficult to say to a physician than a nurse if something felt odd with their treatment or care and/or if they believed the healthcare professional had made mistakes. This finding is in line with previous research ${ }^{23}$ and is usually explained with reference to the hierarchy of the healthcare system. ${ }^{34-38}$ However, another explanation could be that the patients have more contact with nurses and develop a more personal relationship with them, thus making it easier to communicate more openly. ${ }^{39}$ Conversely, a good relationship can also inhibit the patients' willingness to raise awareness about safety issues, in fear of damaging the relationship with the individual healthcare professional. ${ }^{40}$

In our study, over three quarters of the respondents who reported having sustained harm in the last 10 years believed the harm in the latest harm episode 'could' or 'could possibly' have been avoided if the healthcare professionals had listened to them. This is comparable with a nationwide survey conducted in the USA in which two-thirds of the respondents who reported that they had been harmed when receiving care said that one contributing factor was that the healthcare professionals had not listened to them. ${ }^{41}$ Another US study involving nearly 700 patients who had been harmed by preventable adverse events found that healthcare professionals "failed to effectively communicate with them both before and after the adverse event". ${ }^{42}$ Clearly, the patient-professional relationship and communication is of great importance for patient safety. ${ }^{43-45}$ However, we did not investigate other factors of potential relevance for avoiding harm. Hence, our findings concerning the importance of not being listened to for avoiding harm should be interpreted with caution.

A Swedish study by Ringdal et $a l^{46}$ on patients' involvement in safety activities showed that patients felt safe in their care if they were given opportunities to share their feelings, thoughts and information, and perceived that the healthcare professionals listened to them. Although patient safety is usually discussed in terms of 'objective' safety, typically measured as various forms of adverse events, there is also a subjective side to patient safety, that is, the feelings of being safe. The Ringdal et al study $^{46}$ implies that subjective safety may positively influence objective safety if there is a climate that facilitates patient involvement. A UK study by Lawton $e t a l^{47}$ found a strong correlation between objective safety, as measured by harmfree care, and patients' perceptions of how a ward or hospital performed on a number of aspects known to contribute to patient safety incidents. One in six of the regular patients in our study reported that they had experienced harm in healthcare in the last 10 years. A national Swedish study by Soop et $a l^{48}$ estimated the proportion of adverse events to be $12 \%$, of which $70 \%$ were considered preventable. However, that study and our study are not directly comparable because adverse events do not always lead to harm. Also, the Soop et al study ${ }^{48}$ reviewed medical records to determine the number of adverse events and preventability, whereas we used self-reports by asking patients. Furthermore, there is likely a discrepancy in the interpretation of the meaning of harm between patients and healthcare professionals. Some studies have shown that patients mostly identify problems that can be classified as service and/or quality-related problems as harm, that is, lack of respect, long waiting time and communication problems. ${ }^{10} 184950$ However, other studies have shown that patients are capable of identifying adverse events that affect their care. ${ }^{5152}$

A comparison was made between patients who have filed a complaint about being harmed in healthcare and regular patients. We found that, compared with regular patients, complainants considered it was more difficult to ask questions about their illness or treatment and to say to healthcare professionals if something seems odd in their care or treatment. The complainants also agreed to a greater extent to the statement that patients have a responsibility to make healthcare professionals aware of shortcomings in the care. Due to the cross-sectional design of the study, we can only speculate whether the complainants found it hard to interact with healthcare professionals before being harmed (which led to the complaint) or if the experience of being harmed made them more reluctant to complain. Previous research has shown that complainants who have been harmed by adverse events can be very distrusting of healthcare. A Swedish study ${ }^{53}$ of 618 complaints from a Patient Advisory Committee found that less than $30 \%$ of the complainants were satisfied with the healthcare professionals' statements about the complaint. According to Kent, ${ }^{53}$ complainants often experience strong feelings of disappointment, grief, humiliation, anger and bitterness directed towards healthcare and believe that healthcare professionals protect each other rather than objectively investigate the complaint.

The findings from the present study raise questions of relevance for both research and practice. In future studies, it would be interesting to further explore issues concerning experienced harm and avoidability of the harm, especially from the patients' perspective. It is relevant to investigate how patients themselves believe they can contribute to safer care using a qualitative approach to obtain a deeper and more nuanced understanding of patient perceptions. Further, more knowledge is needed on the effectiveness of various interventions to increase patient participation in meetings with healthcare professionals. Complainants and 
regular patients agree that patients can contribute to safer care by interacting with healthcare professionals in regular meetings in healthcare and they believe that it is easier for patients to ask questions if they are encouraged to do so. This encouragement could possibly take the form of healthcare professionals simply informing patients that questions are welcome or by handing out information on emphasising the importance of asking questions and by allowing time for questions. Still, research is needed to investigate what might be most effective for different patients and circumstances.

The study has some limitations that should be taken into account when interpreting the results. Although some of our findings are consistent with those of studies conducted in other countries, generalisability beyond Swedish healthcare may be limited due to differences in the healthcare systems. The response rates for the two patient groups were modest (54\% for complainants and 59\% for regular patients), and a study limitation was the inability to analyse the non-responding patients. It is well known that more motivated and opinionated people are more likely to respond to surveys. ${ }^{54}$ Hence, it is likely that those who did respond to the survey have stronger opinions on patient participation, although it is difficult to speculate how or the extent to which this had an impact on the results. Some questions concerned the respondents' experiences with regard to how easy or difficult it usually was for them to perform specific behaviours (eg, asking questions), yet attitudes and beliefs concerning behaviours are not necessarily translated into actual behaviours. Further, a majority of the patients in the study were ambulatory patients. Patients' illness influences their willingness to become involved in their treatment or care of potential relevance for patient safety, so it might be presumed that healthier patients in primary care are more likely than hospitalised inpatients to intervene with healthcare professionals. ${ }^{16}$ Concerning the complainants, we do not know the subject of their complaints or whether they were found to be eligible for further investigation by the HSCI. We did not define 'harm' in the questionnaire, which means that some respondents may have interpreted this as service quality lapses or emotional injuries (eg, frustration or not feeling respected), as discussed by Rathert et al, ${ }^{32}$ potentially leading to over-reporting of harm. Hence, it is difficult to draw firm conclusions regarding the prevalence of harm among the study participants based on the responses to our questions. It might have been possible to give the respondents an opportunity to describe and specify their perceived harm, to allow for categorisations of harm. It might also be considered a limitation that respondents were asked to report on the perceived avoidability of harm related only to the last experience of harm. They could possibly have experienced more than one harm episode in the last 10 years, but we considered it to be easier from a respondent perspective to relate the avoidability to a specific harm episode rather than providing an overall answer concerning avoidability in general. The study concerns patient involvement and could have been enhanced by involving patients in different aspects of the research. While patients were involved in the questionnaire development, the study might have benefited from involving them earlier in the research process.

\section{CONCLUSIONS}

In conclusion, we found that most respondents believed that healthcare professionals can facilitate patient interaction and increase patient safety by encouraging patients to ask questions and take an active part in their care. Many respondents agreed that patients can contribute to safer care by asking questions regarding their illness, treatment or care. Complainants found it harder than regular patients to intervene with healthcare professionals. A large proportion of respondents who perceived that they had been harmed in healthcare believed that the harm could have been avoided if healthcare professionals had listened to them. Further research will need to identify strategies to support such questioning in routine practice and ensure that it achieves its intended goals.

\section{Author affiliations}

${ }^{1}$ Cardiology and Speciality Medicine Centre, Region Ostergotland, Linkoping, Sweden

${ }^{2}$ Department of Medical and Health Sciences, Linköping University, Linkoping, Sweden

${ }^{3}$ Research and Development Unit, Region Ostergotland, Linkoping, Sweden ${ }^{4}$ Faculty of Health and Life Sciences, Linnaeus University, Kalmar, Sweden

${ }^{5}$ The Research Section, Kalmar County Council, Kalmar, Sweden

${ }^{6}$ Department of Nursing, School of Health and Welfare, Jonkoping University, Jonkoping, Sweden

${ }^{7}$ Department of Clinical Neurophysiology, Region Ostergotland, Linkoping, Sweden

${ }^{8}$ Social Determinants of Health Research Center, Qazvin University of Medical Sciences, Qazvin, Iran

Acknowledgements Many thanks to Marika Wenemark who assisted us in the development of the questionnaire and study approach, and to Narcisa Kadric Muminovic who helped us with the Think-aloud interviews to test the questionnaire.

Contributors CE, JS, KGIS and PN designed the study and the questionnaire. CE and KGIS administered the data collection. $\mathrm{KA}$ conducted the analysis, with additional statistical input from AP. CE, JS, KGIS and PN wrote the first draft of the manuscript, and $\mathrm{KA}, \mathrm{AB}$ and $\mathrm{AP}$ provided critical revisions. All authors approved the final version of the paper for submission.

Funding This study was funded by The Swedish Research Council for Health, Working Life and Welfare, FORTE, 20144567.

Competing interests None declared.

Patient consent for publication Not required.

Ethics approval This study was approved by the Regional Ethical Board in Linköping (Dnr 2016/80-31).

Provenance and peer review Not commissioned; externally peer reviewed.

Data availability statement Data are available on reasonable request. 
Open access This is an open access article distributed in accordance with the Creative Commons Attribution Non Commercial (CC BY-NC 4.0) license, which permits others to distribute, remix, adapt, build upon this work noncommercially, and license their derivative works on different terms, provided the original work is properly cited, appropriate credit is given, any changes made indicated, and the use is noncommercial. See: http://creativecommons.org/licenses/by-nc/4. $0 /$.

\section{REFERENCES}

1 Vincent CA, Coulter A. Patient safety: what about the patient? Qual Saf Health Care 2002;11:76-80.

2 Longtin Y, Sax H, Leape LL, et al. Patient participation: current knowledge and applicability to patient safety. Mayo Clin Proc 2010;85:53-62.

3 Coulter A, Ellins J. Patient-focused interventions: a review of the evidence. London: The Health Foundation, 2006.

4 Vincent C, Davis R. Patients and families as safety experts. CMAJ 2012;184:15-16.

5 World Health Organization. Patients for Patient Safety. Partnerships for Safer Health Care. Geneva: WHO, 2013.

6 Joint Commission. Speak up initiatives, 2015. Available: https://www.jointcommission.org/speakup.aspx [Accessed 28 May 2018].

7 National Board of Health and Welfare. Din skyldighet att informera och göra patienten delaktig [Your obligation to inform and involve the patient], 2015. Available: http://www. socialstyrelsen.se/Lists/Artikelkatalog/Attachments/19801/ 2015-4-10.pdf [Accessed 3 Nov 2017].

8 SALAR. Patientmedverkan [Patient Participation], 2018. Available: http://skl.se/halsasjukvard/patientsakerhet/ patientmedverkan.743.html [Accessed 28 May 2018].

9 Kuzel AJ, Woolf SH, Gilchrist VJ, et al. Patient reports of preventable problems and harms in primary health care. Ann Fam Med 2004;2:333-40.

10 Watt I, Birks Y, Entwistle V. A review of strategies to promote patient involvement, a study to explore patient's views and attitudes and a pilot study to evaluate the acceptability of selected patient involvement strategies. York University of York; 2009.

11 Doherty C, Stavropoulou C. Patients' willingness and ability to participate actively in the reduction of clinical errors: a systematic literature review. Soc Sci Med 2012;75:257-63.

12 Entwistle VA, McCaughan D, Watt IS, et al. Speaking up about safety concerns: multi-setting qualitative study of patients' views and experiences. Qual Saf Health Care 2010;19:e33.

13 Hibbard JH, Peters E, Slovic P, et al. Can patients be part of the solution? Views on their role in preventing medical errors. Med Care Res Rev 2005;62:601-16.

14 Schwappach DLB, Wernli M, Am I. Am I (un)safe here? Chemotherapy patients' perspectives towards engaging in their safety. BMJ Qual Saf 2010;19:e9-6.

15 Sahlström M, Partanen P, Rathert C, et al. Patient participation in patient safety still missing: patient safety experts' views. Int $J$ Nurs Pract 2016;22:461-9.

16 Davis RE, Jacklin R, Sevdalis N, et al. Patient involvement in patient safety: what factors influence patient participation and engagement? Health Expect 2007;10:259-67.

17 Davis RE, Sevdalis N, Vincent CA. Patient involvement in patient safety: how willing are patients to participate? BMJ Qual Saf 2011;20:108-14.
18 Severinsson E, Holm AL. Patients' role in their own safety-a systematic review of patient involvement in safety. Open J Nurs 2015;05:642-53.

19 Health and Social Care Inspectorate. About the Health and Social Care Inspectorate, 2015. Available: https://www.ivo.se/ om-ivo/other-languages/english/ [Accessed 28 May 2018].

20 Russ SJ, Rout S, Caris J, et al. The WHO surgical safety checklist: survey of patients' views. BMJ Qual Saf 2014;23:939-46.

21 Nilsen P, Skagerström J, Ericsson C, et al. Många faktorer påverkar om patienter kan medverka till säkrare vård Intervjustudie visar läkares och sjuksköterskors perspektiv [Many factors affect whether patients can contribute to safer care. Interview study shows the doctors' and nurses' perspective]. Läkartidningen 2017;114.

22 Skagerström J, Ericsson C, Nilsen P, et al. Patient involvement for improved patient safety: a qualitative study of nurses' perceptions and experiences. Nurs Open 2017;4:230-9.

23 Bowling A. Just one question: if one question works, why ask several? J Epidemiol Community Health 2005;59:342-5.

24 Ware JE, Gandek B. Overview of the SF-36 health survey and the International Quality of Life Assessment (IQOLA) project. J Clin Epidemiol 1998;51:903-12.

25 Sullivan M, Karlsson J, Ware JE. The Swedish SF-36 Health Survey-I. Evaluation of data quality, scaling assumptions, reliability and construct validity across general populations in Sweden. Soc Sci Med 1995;41:1349-58.

26 Willis GB. Cognitive interviewing a "how to" guide, 1999. Available: https://www.hkr.se/contentassets/9ed7b1b3997e4bf4 baa8d4eceed5cd87/gordonwillis.pdf [Accessed 4 Dec 2017].

27 Vahdat S, Hamzehgardeshi L, Hessam S, et al. Patient involvement in health care decision making: a review. Iran Red Crescent Med J 2014; 16:e12454.

28 Rainey H, Ehrich K, Mackintosh N, et al. The role of patients and their relatives in 'speaking up' about their own safety-a qualitative study of acute illness. Health Expect 2015;18:392-405.

29 Wright J, Lawton R, O’Hara J, et al. Improving patient safety through the involvement of patients: development and evaluation of novel interventions to engage patients in preventing patient safety incidents and protecting them against unintended harm. Programme Grants Appl Res 2016;4:1-296.

30 Schildmeijer K, Nilsen P, Ericsson C, et al. Determinants of patient participation for safer care: a qualitative study of physicians' experiences and perceptions. Health Sci Rep 2018;1.

31 Grünloh C, Myreteg G, Cajander Åsa, et al. "Why do they need to check me?" Patient participation through ehealth and the doctor-patient relationship: qualitative study. J Med Internet Res 2018;20:e11.

32 Rathert C, Brandt J, Williams ES. Putting the 'patient' in patient safety: a qualitative study of consumer experiences. Health Expect 2012;15:327-36.

33 O'Connor E, Coates HM, Yardley IE, et al. Disclosure of patient safety incidents: a comprehensive review. Int J Qual Health Care 2010;22:371-9.

34 Leape LL, Shore MF, Dienstag JL, et al. Perspective: a culture of respect, part 1: the nature and causes of disrespectful behavior by physicians. Acad Med 2012;87:845-52.

35 Skela Savič B, Pagon M. Relationship between nurses and physicians in terms of organizational culture: who is responsible for subordination of nurses? Croat Med J 2008;49:334-43. 
36 Hall P. Interprofessional teamwork: professional cultures as barriers. J Interprof Care 2005;19 Suppl 1:188-96.

37 Johnson S, Kring D. Nurses' perceptions of nurse-physician relationships: medical-surgical vs. intensive care. Medsurg Nurs 2012;21:343-7.

38 Siedlecki SL, Hixson ED. Relationships between nurses and physicians matter. Online J Issues Nurs 2015;20.

39 Vinall-Collier K, Madill A, Firth J. A multi-centre study of interactional style in nurse specialist- and physicianled rheumatology clinics in the UK. Int J Nurs Stud 2016;59:41-50.

40 Hrisos S, Thomson R. Seeing it from both sides: do approaches to involving patients in improving their safety risk damaging the trust between patients and healthcare professionals? An interview study. PLOS ONE 2013;8:e80759.

$41 \mathrm{IHI} / \mathrm{NPSF}, \mathrm{NORC}$ at the University of Chicago and IHI/NPSF Lucian Leape Institute. Americans' experiences with medical errors and views on patient safety. Cambridge, MA: Institute for Healthcare Improvement and NORC at the University of Chicago, 2017.

42 Southwick FS, Cranley NM, Hallisy JA. A patient-initiated voluntary online survey of adverse medical events: the perspective of 696 injured patients and families. BMJ Qual Saf 2015;24:620-9.

43 Brennan N, Barnes R, Calnan M, et al. Trust in the health-care provider-patient relationship: a systematic mapping review of the evidence base. Int J Qual Health Care 2013;25:682-8.

44 Ridd M, Shaw A, Lewis G, et al. The patient-doctor relationship: a synthesis of the qualitative literature on patients' perspectives. Br J Gen Pract 2009;59:e116-33.

45 Daker-White G, Hays R, McSharry J, et al. Blame the patient, blame the doctor or blame the system? A meta-synthesis of qualitative studies of patient safety in primary care. PLoS One 2015;10:e0128329.

46 Ringdal M, Chaboyer W, Ulin K, et al. Patient preferences for participation in patient care and safety activities in hospitals. BMC Nurs 2017;16.

47 Lawton R, O'Hara JK, Sheard L, et al. Can staff and patient perspectives on Hospital safety predict harm-free care? An analysis of staff and patient survey data and routinely collected outcomes. BMJ Qual Saf 2015;24:369-76.

48 Soop M, Fryksmark U, Köster M, et al. The incidence of adverse events in Swedish hospitals: a retrospective medical record review study. Int J Qual Health Care 2009;21:285-91.

49 Harrison R, Walton M, Manias E, et al. The missing evidence: a systematic review of patients' experiences of adverse events in health care. Int J Qual Health Care 2015;27:424-42.

50 Lang S, Velasco Garrido M, Heintze C. Patients' views of adverse events in primary and ambulatory care: a systematic review to assess methods and the content of what patients consider to be adverse events. BMC Fam Pract 2016;17.

51 Weingart SN, Pagovich O, Sands DZ, et al. What can hospitalized patients tell us about adverse events? Learning from patient-reported incidents. J Gen Intern Med 2005;20:830-6.

52 Zhu J, Stuver SO, Epstein AM, et al. Can we rely on patients' reports of adverse events? Med Care 2011;49:948-55.

53 Kent A. Dismissing the disgruntled: Swedish patient complaints management. Int J Health Care Qual Assur 2008;21:487-94.

54 Brodie D, Williams J, Owens R. Research methods for the health sciences. Amsterdam, The Netherlands: Harwood Academic Publishers, 1997. 